\title{
The Insulinotropic Potency of Fatty Acids Is Influenced Profoundly by Their Chain Length and Degree of Saturation
}

\author{
Daniel T. Stein, ${ }^{*}$ Brent E. Stevenson, ${ }^{*}$ Michael W. Chester, ${ }^{*}$ Majid Basit, ${ }^{*}$ Murphy B. Daniels, ${ }^{*}$ Stephen D. Turley, \\ and J. Denis McGarry ${ }^{\star}$ \\ *Department of Internal Medicine and ${ }^{\ddagger}$ Department of Biochemistry, Center for Diabetes Research, University of Texas Southwestern \\ Medical Center at Dallas, Dallas, Texas 75235
}

\begin{abstract}
Lowering of the elevated plasma FFA concentration in 1824-h fasted rats with nicotinic acid (NA) caused complete ablation of subsequent glucose-stimulated insulin secretion (GSIS). Although the effect of NA was reversed when the fasting level of total FFA was maintained by coinfusion of soybean oil or lard oil (plus heparin), the more saturated animal fat proved to be far more potent in enhancing GSIS. We therefore examined the influence of individual fatty acids on insulin secretion in the perfused rat pancreas. When present in the perfusion fluid at $0.5 \mathrm{mM}$ (in the context of $1 \%$ albumin), the fold stimulation of insulin release from the fasted pancreas in response to $\mathbf{1 2 . 5} \mathrm{mM}$ glucose was as follows: octanoate $\left(\mathrm{C}_{8: 0}\right)$, 3.4; linoleate $\left(\mathrm{C}_{18: 2}\right.$ cis/cis $), 5.3$; oleate

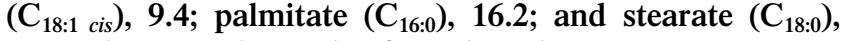
21.0. The equivalent value for palmitoleate $\left(C_{16: 1 ~ c i s}\right)$ was 3.1. A cis $\rightarrow$ trans switch of the double bond in the $C_{16: 1}$ and $C_{18: 1}$ fatty acids had only a modest, if any, impact on their potency. A similar profile emerged with regard to basal insulin secretion ( $3 \mathrm{mM}$ glucose). When a subset of these fatty acids was tested in pancreases from fed animals, the same rank order of effectiveness at both basal and stimulatory levels of glucose was seen.

The findings reaffirm the essentiality of an elevated plasma FFA concentration for GSIS in the fasted rat. They also show, however, that the insulinotropic effect of individual fatty acids spans a remarkably broad range, increasing and decreasing dramatically with chain length and degree of unsaturation, respectively. Thus, for any given level of glucose, insulin secretion will be influenced greatly not only by the combined concentration of all circulating (unbound) FFA, but also by the makeup of this FFA pool. Both factors will likely be important considerations in understanding the complex interplay between the nature of dietary fat and whole body insulin, glucose, and lipid dynamics. (J. Clin. Invest. 1997. 100:398-403.) Key words: saturated fatty acids - unsaturated fatty acids • insulin secretion - hyperinsulinemia $•$ hyperlipidemia
\end{abstract}

Address correspondence to J. Denis McGarry, Ph.D., Professor of Internal Medicine and Biochemistry, U.T. Southwestern Medical Center at Dallas, 5323 Harry Hines Blvd., Dallas, TX 75235. Phone: 214648-3484; FAX: 214-648-2843.

Received for publication 14 February 1997 and accepted in revised form 18 April 1997.

J. Clin. Invest.

(C) The American Society for Clinical Investigation, Inc.

0021-9738/97/07/0398/06 \$2.00

Volume 100, Number 2, July 1997, 398-403

\section{Introduction}

Although FFA have long been known to be stimulatory towards the pancreatic $\beta$ cell (1-6), only recently has it become clear that under certain circumstances they are absolutely required for glucose-stimulated insulin secretion (GSIS). ${ }^{1}$ Thus, when 18-24-h fasted rats were infused with the antilipolytic agent nicotinic acid (NA) to lower their elevated plasma FFA concentration, insulin secretion in response to a subsequent intravenous glucose challenge was essentially ablated (7). On the other hand, when NA-treated animals received a coinfusion of Intralipid plus heparin, a maneuver that maintained a high plasma FFA level, GSIS became supranormal. In fed animals, GSIS was equally robust regardless of whether their initially lower plasma FFA level was further reduced by NA infusion. In this case, however, artificial elevation of the FFA concentration produced a massive stimulation of insulin secretion (7).

Because Intralipid is prepared from soybean oil and thus generates a mixture of long chain, mainly unsaturated, fatty acids, we asked how other types of fatty acids would behave in terms of their ability to enhance GSIS. The studies outlined below, performed both in vivo and in the perfused rat pancreas, reveal that the insulinotropic potency of fatty acids is influenced profoundly by their chain length and degree of saturation.

\section{Methods}

Animals. Male Sprague-Dawley rats weighing $\sim 300 \mathrm{~g}$ (Harlan SpragueDawley Co., Indianapolis, IN) were used throughout. The rats were maintained on a light/dark cycle (lights on 1000-2200 h) with ad libitum access to standard rodent chow containing $4 \%$ fat (Harlan Teklad, Madison, WI). For in vivo studies, animals were fitted with carotid artery and jugular vein catheters $5 \mathrm{~d}$ before use as described previously (7). Fasted rats were deprived of food from $1800 \mathrm{~h}$ the night before experiments.

Preparation of lipid emulsions. The following components were placed in a 50-ml plastic tube: $24 \mathrm{ml}$ of $2.5 \%$ (wt/vol) glycerol, $0.36 \mathrm{~g}$ of phosphatidylcholine (P-5394 Sigma Chemical Co., St. Louis, MO), $0.3 \mathrm{ml}$ of penicillin-streptomycin solution (\#P0781; Sigma Chemical Co.), and $6 \mathrm{~g}$ of either soybean oil (\#S-7381; Sigma Chemical Co.) or lard oil (\#L-0657; Sigma Chemical Co.). After heating at $80^{\circ} \mathrm{C}$ for $\sim 10$ min, the mixture was sonicated for $3 \times 1 \mathrm{~min}$ (with 1 -min pauses) at a power setting of seven (Sonicator W-220F with a microtip probe; Heat Systems Ultrasonics, Plainview, NY). The emulsions formed were kept at $4^{\circ} \mathrm{C}$ for 3-4 d during which they remained homogeneous and stable.

Hyperglycemic clamp. On the morning of experiments $(\sim 0900 \mathrm{~h})$, catheters were flushed with small amounts of heparinized saline (25 $\mathrm{U} / \mathrm{ml}$ ), after which the arterial line was connected for infusion of test

1. Abbreviations used in this paper: GSIS, glucose-stimulated insulin secretion; NA, nicotinic acid. 
substances and replacement blood; the venous line was used for sampling, and was kept patent by the infusion of heparinized saline at 1 $\mathrm{ml} / \mathrm{h}$. The rest of the clamp procedure was basically as described earlier (7), with two modifications: (a) the equilibration (basal) phase was increased from 60 to $90 \mathrm{~min}$; and (b) the postglucose challenge phase was reduced from 60 to $30 \mathrm{~min}$. Blood samples were taken for analysis at $-90,0,5,10,15,20,25$, and $30 \mathrm{~min}$.

When used, the lipid emulsion (soybean or lard oil) was infused from $-90 \mathrm{~min}$ onwards at a rate of $0.54 \mathrm{ml} / \mathrm{h}$ per $100 \mathrm{~g}$ body wt, together with intravenous boluses of 100,50 , and $25 \mathrm{U}$ of heparin at $-90,-70$, and $-40 \mathrm{~min}$, respectively. Control animals received the phospholipid emulsion lacking triacylglycerol.

NA (Sigma Chemical Co.) was dissolved in $150 \mathrm{mM} \mathrm{NaCl}$ containing $10 \%$ dialyzed rat serum at a concentration of $2 \mathrm{mM}(\mathrm{pH}$ adjusted to $\sim 7$ ), and was given as a $0.25-\mathrm{ml}$ bolus at $-75 \mathrm{~min}$, and at 1.5 $\mathrm{ml} / \mathrm{h}$ thereafter. Control animals received the vehicle only.

Pancreas perfusion. Pancreases were perfused as described (8). The basal perfusate, maintained at $37^{\circ} \mathrm{C}$ under $95 \% \mathrm{O}_{2} / 5 \% \mathrm{CO}_{2}$, contained KRB, pH 7.4, $3 \mathrm{mM}$ glucose, 4.5\% (wt/vol) Dextran T-70, and $1 \%(\mathrm{wt} / \mathrm{vol})$ fatty acid-free bovine serum albumin. When used, fatty acids were present throughout the perfusion as their sodium salts at a concentration of $0.5 \mathrm{mM}$. Sample collection began after an equilibration period of $15 \mathrm{~min}$ (designated time 0 ). $10 \mathrm{~min}$ later glucose was infused from a syringe to raise its concentration in the perfusate to 12.5 $\mathrm{mM}$. At the 40-min point this infusion was stopped, and samples were collected for a final $10 \mathrm{~min}$. The flow rate was $\sim 1.5 \mathrm{ml} / \mathrm{min}$. The effluent, collected every $2 \mathrm{~min}$ in chilled tubes, was stored at $-20^{\circ} \mathrm{C}$ until assayed for insulin (generally within 3-5 d). Perfusions in the absence and presence of the various fatty acids were carried out in random order.

Analyses on plasma and perfusion fluid. Glucose concentrations were determined (glucose analyzer II; Beckman Instruments, Fullerton, CA). Fatty acids were measured using a calorimetric kit (Boehringer Mannheim Biochemicals, Indianapolis, IN), but using our own palmitate standard (having found after the fact that the kit standards used in our earlier study [7] antifactually inflated sample fatty acid concentrations by $\sim 40 \%)$. The insulin assay is described in detail elsewhere (7).

Statistical analysis. Stimulated insulin values, summed from time +5 to $+30 \mathrm{~min}$, were compared using Bonferroni corrected $t$-tests (Sigma Stat; Jandel Scientific, San Rafael, CA).

\section{Results}

In vivo studies. As seen from Fig. 1, the acute induction of hyperglycemia in control fasted rats caused a brisk increase in the plasma insulin concentration (from $0.06 \mathrm{ng} / \mathrm{ml}$ at $0 \mathrm{~min}$ to 2.24 $\mathrm{ng} / \mathrm{ml}$ at $+5 \mathrm{~min}$ ) which then waned with time $(C)$. As expected, this increase was accompanied by a sharp fall in the circulating FFA level $(B)$. By contrast, and in keeping with our earlier report (7), in animals receiving NA from $-90 \mathrm{~min}$, the plasma FFA concentration had fallen sharply by the 0 min time point, and, as a result, insulin secretion in response to the glucose challenge was completely suppressed (Fig. 1, $B$ and $C$ ). When NA-treated rats received a coinfusion of soybean oil plus heparin to maintain their FFA level at its elevated fasting value, however, there was a significant insulin response between 0 and $+5 \mathrm{~min}$ (from 0.07 to $0.81 \mathrm{ng} / \mathrm{ml}$ ), and from +10 min onwards the plasma concentration of the hormone continued to increase, reaching a value of $4.4 \mathrm{ng} / \mathrm{ml}$ at $+30 \mathrm{~min}$ compared with $1.2 \mathrm{ng} / \mathrm{ml}$ in the control group. When lard oil was used in place of soybean oil, the pattern of insulin secretion changed markedly. Not only was the acute insulin response to glucose completely restored, but, in addition, there was an exuberant second phase of secretion, such that by +30 min the

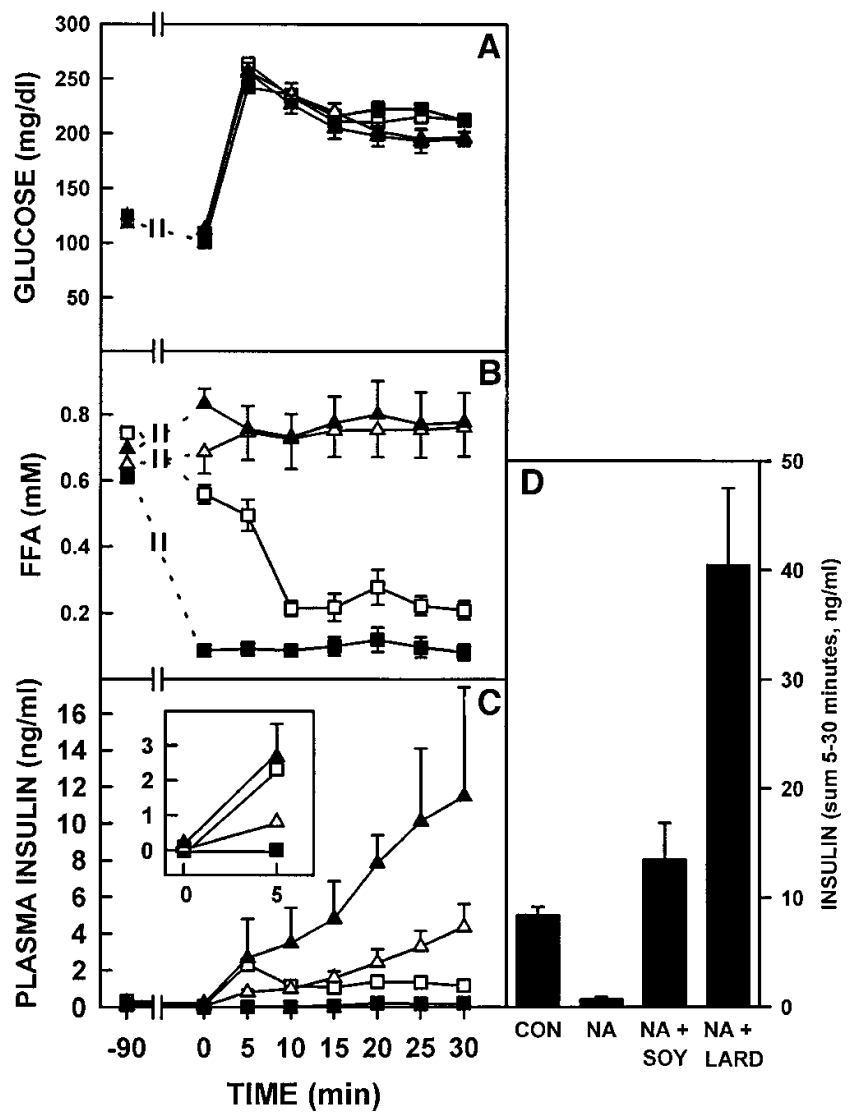

Figure 1. Effect of soybean oil (SOY) and lard oil ( $L A R D)$ infusion on the plasma insulin response in NA-treated fasted rats. Animals received the indicated infusions from $-90 \mathrm{~min}$ (lipid) or $-75 \mathrm{~min}(\mathrm{NA})$ onwards as described in Methods. At 0 min a hyperglycemic clamp was initiated by intravenous administration of glucose. Values are means \pm SEM for four to eight animals in each group. When not shown, standard error bars are contained within the symbol. Symbols are as follows: $\boldsymbol{\Delta}, \mathrm{NA}+\mathrm{LARD} ; \triangle$, NA + SOY; $\mathbf{\square}, \mathrm{NA} ; \square$, control.

plasma level had reached $11.5 \mathrm{ng} / \mathrm{ml}$ (Fig. $1 C$ ). Fig. $1 D$ shows the sum of each measured insulin concentration after the glucose challenge, which may be taken as a reflection of overall hormone secretion during the clamp period. Lowering the FFA level by NA treatment profoundly reduced the insulin value from $8.24 \pm 1.09$ to $0.70 \pm 0.22 \mathrm{ng} / \mathrm{ml}$ (means \pm SEM; $P<$ $0.0001)$. GSIS, however, was completely restored by coadministration of soybean oil $(13.5 \pm 3.3 \mathrm{ng} / \mathrm{ml}$; NS compared with control) and became supranormal when soybean oil was replaced by lard oil $(40.4 \pm 7.0 \mathrm{ng} / \mathrm{ml} ; P<0.0005$ and $0.005 \mathrm{com}-$ pared with the control and soybean oil groups, respectively).

The reproducible finding that the acute $(+5-\mathrm{min})$ insulin response to glucose in rats receiving NA plus soybean oil was only $\sim 30 \%$ of that in control or NA plus lard oil-treated animals (Fig. $1 C$, inset), despite similar total plasma FFA concentrations in all three groups (Fig. $1 \mathrm{~B}$ ), was reminiscent of previous results in which Intralipid was the infused emulsion (7). We suspected that this result might have stemmed from a difference in the nature of the fatty acids in the circulation before the glucose challenge. Accordingly, the total lipids were extracted from plasma of similarly treated rats, and were fractionated using silica Sep-Pak columns (Waters Associates, Mil- 
Table I. Plasma FFA Composition in Control, Soybean Oiland Lard Oil-infused Fasted Rats

\begin{tabular}{lccc}
\hline \multicolumn{1}{c}{ Fatty acid } & Controls & NA + soybean oil & NA + lard oil \\
\hline & \multicolumn{3}{c}{ \% of total } \\
1. Palmitic (C16:0) & 25.9 & 10.5 & 15.9 \\
2. Stearic (C18:0) & 9.7 & 4.8 & 4.3 \\
3. Oleic (C18:1) & 23.1 & 15.5 & 25.9 \\
4. Linoleic (C18:2) & 24.8 & 36.9 & 16.2 \\
5. Linolenic (C18:3) & 1.7 & 5.3 & 0.9 \\
Ratio $\frac{3+4+5}{1+2}$ & 1.40 & 3.77 & 2.13 \\
\end{tabular}

Rats were treated as in Fig. 1, and blood was collected for analysis at the 0 -min time point. Values refer to the five most abundant fatty acids in pooled plasma from four to five animals in each group.

ford, MA) (9). The nonesterified fatty acids thus obtained were then analyzed by conventional gas-liquid chromatography. The major species found are listed in Table I. It is seen that the ratio of unsaturated to saturated fatty acids was markedly lower in the lard oil- versus soybean oil-treated rats, and that the pattern in the former group more closely resembled that in the untreated animals.

Studies with the perfused pancreas. The very different effectiveness of the two lipid emulsions in enhancing GSIS in vivo clearly pointed to a differential insulinotropic potency of saturated versus unsaturated fatty acids. To explore this notion further we turned to the perfused pancreas preparation in which the impact of individual fatty acids on GSIS could be examined directly. For this purpose, insulin secretion was measured in response to an increase in the perfusate glucose concentration from 3 to $12.5 \mathrm{mM}$ in the absence or presence of different fatty acids, each of which was added to the medium at a concentration of $0.5 \mathrm{mM}$.

The data of Fig. 2 reinforce the now well-established point that, when isolated from the whole animal, the pancreas of a previously fasted rat responds very poorly to glucose as the sole insulin secretagogue $(7,10-12)$. While all of the fatty acids tested enhanced both first- and second-phase GSIS in a qualitatively similar manner (Fig. 2, $A$ ), their quantitative potency varied over a remarkable range. Thus, during the high glucose period the fold increase in total insulin secretion over the control value of $6.7 \mathrm{ng}$ was as follows, octanoate $\left(\mathrm{C}_{8: 0}\right) 3.4$; linoleate $\left(\mathrm{C}_{18: 2 \text { cis/cis }}\right)$ 5.3; oleate $\left(\mathrm{C}_{18: 1 \text { cis }}\right)$ 9.4; palmitate $\left(\mathrm{C}_{16: 0}\right)$ 16.2; and stearate $\left(\mathrm{C}_{18: 0}\right) 21.0$ (Fig. $2 \mathrm{~B}$ ). A similar profile was seen with regard to basal hormone secretion (Fig. $2 A$, inset).

The effect of each of the above fatty acids (with the exception of octanoate) was also examined using pancreases from fed rats (Fig. 3). As expected, the total amount of insulin released in response to $12.5 \mathrm{mM}$ glucose alone (37.8 $\mathrm{ng}$ ) was significantly greater than that obtained with the fasted pancreas (note the difference in ordinate scales between Fig. 2 and Fig. 3). Nevertheless, the same rank order emerged with respect to the fold stimulation imparted by the various fatty acids: linoleate, 3.7; oleate, 6.0; palmitate, 7.1; and stearate 12.3 (Fig. 3 $B$ ). Also, the effect of the fatty acids on basal insulin output was now much more apparent, the fold increase ranging from 13 for linoleate to 65 for stearate (Fig. 3 A, inset).
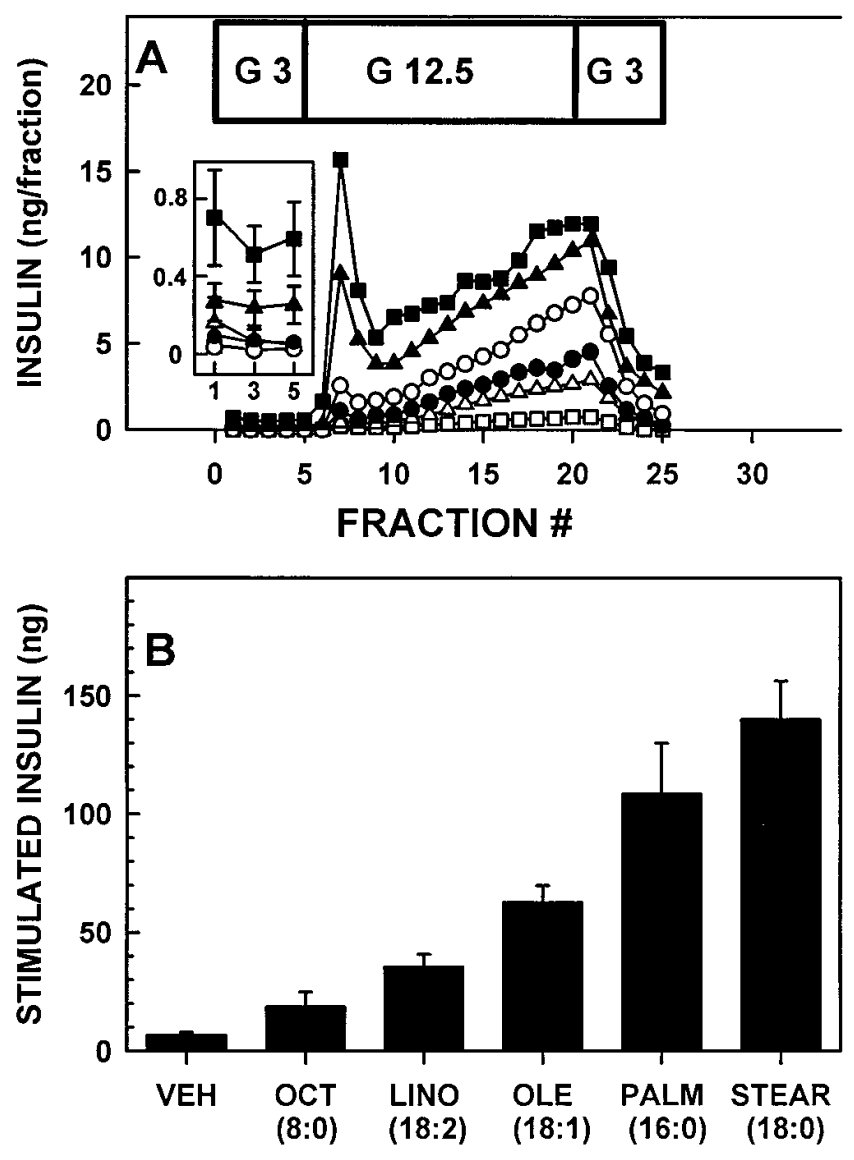

Figure 2. Effect of different fatty acids on GSIS from the perfused pancreas of fasted rats. $(A)$ The concentration of glucose in the perfusion medium was either $3 \mathrm{mM}(G 3)$ or $12.5 \mathrm{mM}(G 12.5)$, and the indicated fatty acid was present at a concentration of $0.5 \mathrm{mM}$ throughout. (B) Total insulin secreted in response to $12.5 \mathrm{mM}$ glucose.

Values are means \pm SEM for five to six perfusions in each group. For clarity, standard error bars have been omitted from $A$. Symbols are as follows: $\mathbf{\square}$, stearic (18:0); $\boldsymbol{\Lambda}$, palmitic (16:0); $\bigcirc$, oleic (18:1); $\boldsymbol{\bullet}$, linoleic (18:2); $\triangle$, octanoic (8:0); $\square$, control.

Taken together, the above findings established that the insulinotropic potency of fatty acids increases dramatically as a function of their chain length and degree of saturation. Both points are confirmed and extended by the studies of Fig. 4, in which an additional variable, namely the effect of geometric isomerism surrounding a given double bond, was also determined. It is seen that, just as oleate was far less effective than stearate, introduction of a single double bond into the palmitate molecule to produce palmitoleate $\left(\mathrm{C}_{16: 1 \text { cis }}\right)$ reduced the fold stimulation of GSIS from 16.2 to 3.1. While there was no significant difference in the effectiveness of oleic $\left(\mathrm{C}_{18: 1 \text { cis }}\right)$ and elaidic $\left(\mathrm{C}_{18: 1 \text { trans }}\right)$ acid, palmitelaidic acid $\left(\mathrm{C}_{16: 1 \text { trans }}\right)$ tended to be more potent (fold stimulation 7.6) than its cis isomer; the difference, however, did not quite reach statistical significance $(P<0.07)$.

\section{Discussion}

The critically important role of fatty acids in pancreatic $\beta$ cell function came into sharper focus recently with the demonstration (7) that in the fasted rat the elevated level of circulating 

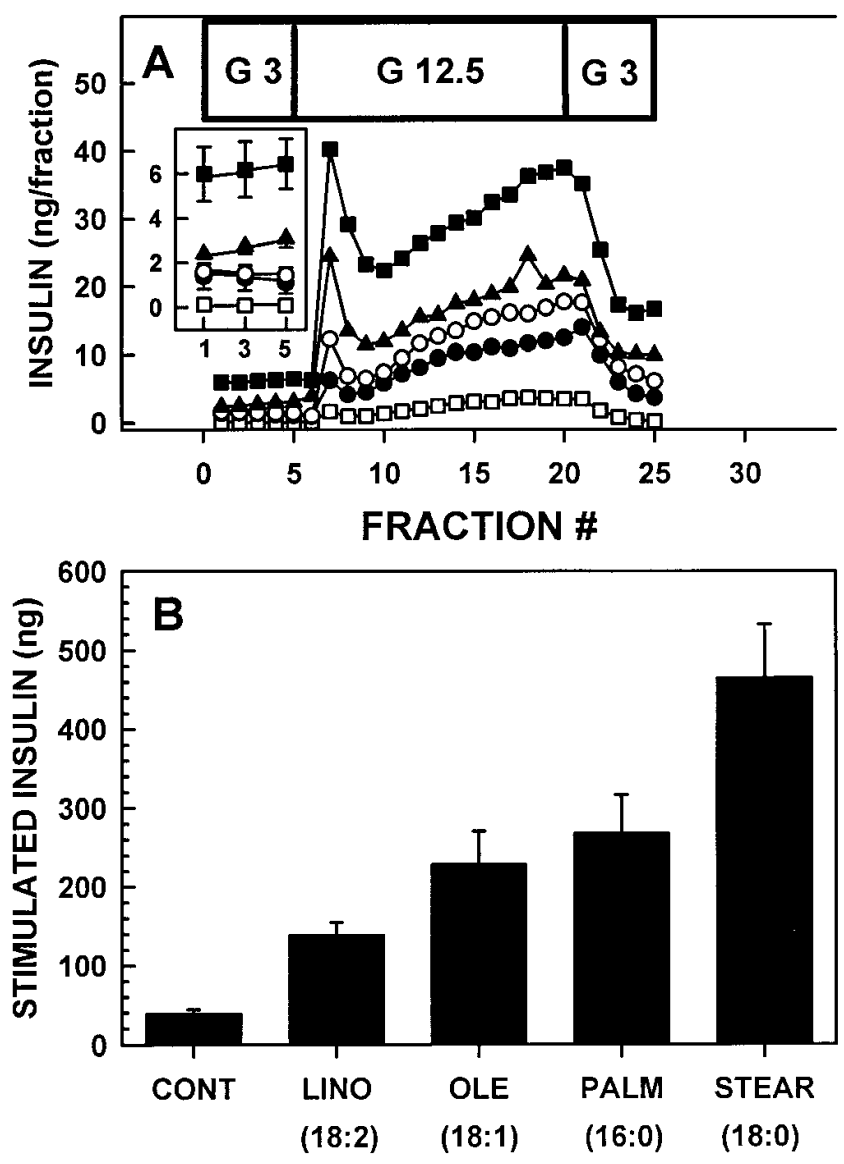

Figure 3. Effect of different fatty acids on GSIS from the perfused pancreas of fed rats. Details are described for Fig. 2. Symbols are as follows: $\mathbf{\square}$, stearic (18:0); $\boldsymbol{\Lambda}$, palmitic (16:0); $\bigcirc$, oleic; $\boldsymbol{\bullet}$, linoleic (18:2); $\square$, control.

FFA is a sine qua non for GSIS. The current work extends this principle to another level by establishing that all fatty acids are not made equal in terms of their insulinotropic potency. Initial clues to this effect came from the following observations made in our earlier study (7). First, in control fasted rats, acute intravenous glucose administration elicited a prompt insulin response that waned with time despite maintenance of continued hyperglycemia using a glucose clamp. (The poor second phase response in this setting stems from the insulin-induced suppression of lipolysis, which removed the fatty acid drive on $\beta$ cell secretion.) Second, prior lowering of the FFA concentration by NA totally abrogated GSIS. Third, artificial elevation of the FFA level in NA-treated rats by coinfusion of Intralipid plus heparin did not fully restore the first phase insulin response to glucose, although it promoted an accelerated second phase of secretion. All of these findings were reproduced in the present work, in which soybean oil, the principal ingredient of Intralipid, was used to maintain a high FFA level in NAtreated animals. When soybean oil was replaced by lard oil, however, (which, like the endogenous FFA in these rats, contains a higher ratio of saturated to unsaturated fatty acids) not only was the acute insulin response to glucose completely normalized, but second-phase insulin secretion now outstripped even that seen with soybean oil infusion by threefold.

The implication from these in vivo studies that GSIS is in-
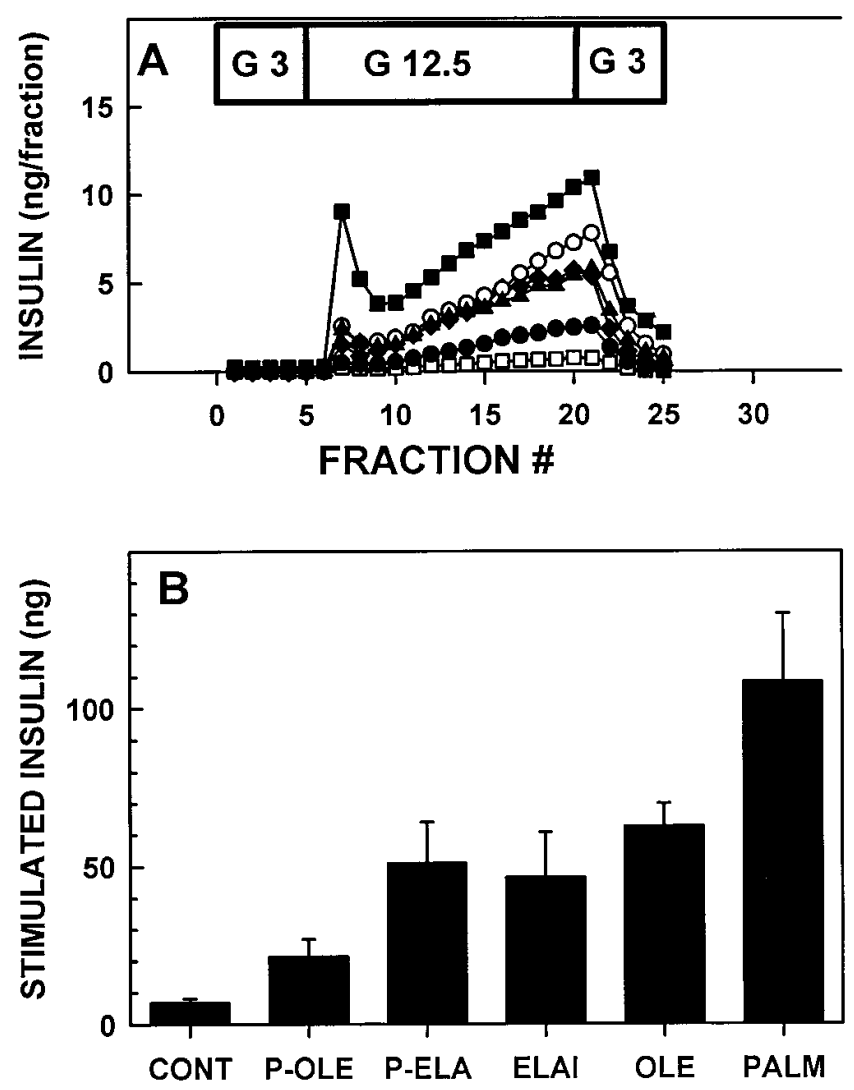

Figure 4. Effect of different fatty acids on GSIS from the perfused pancreas of fasted rats. Details are as described for Fig. 2 and Fig. 3. The data for control, oleate, and palmitate perfusions are taken from Fig. 2. Symbols are as follows: $\bullet$, palmitelaidic; $\boldsymbol{\Lambda}$, elaidic; $\bullet$, palmitoleic; $\mathbf{\square}$, palmitic; $\bigcirc$, oleic; $\square$, control.

fluenced differently by different types of fatty acids was borne out by experiments with the isolated perfused pancreas preparation. When the donor animal was fasted, the characteristic sluggish insulin response to a stimulatory glucose level (12.5 $\mathrm{mM})(7,10-12)$ was confirmed. The simultaneous presence of a fatty acid in the medium $(0.5 \mathrm{mM}$ in a context of $1 \%$ albu$\mathrm{min})$, however, produced a dramatically different picture depending upon the type used. Thus, whereas octanoate $\left(\mathrm{C}_{8: 0}\right)$ enhanced GSIS by 3.4-fold, the stimulus provided by linoleate $\left(\mathrm{C}_{18: 2}\right)$ was 5.3-fold. Even more strikingly, as the number of double bonds in the $\mathrm{C}_{18}$ fatty acid was reduced to 1 and 0 , (i.e. oleate and stearate), the fold enhancement of GSIS rose to 9.4 and 21.0, respectively; the equivalent value for palmitate $\left(\mathrm{C}_{16: 0}\right)$ was 16.2. The various fatty acids also stimulated the low rate of basal insulin secretion (at $3 \mathrm{mM}$ glucose) in roughly the same rank order of effectiveness. A similar profile emerged when the pancreas came from fed animals, but in this case insulin secretion in response to $12.5 \mathrm{mM}$ glucose alone was five to sixfold greater than with the fasted organ, in keeping with previous findings $(7,10-12)$. Moreover, the powerful enhancement of basal insulin secretion was now even more noticeable, reaching 65-fold with stearate. Clearly, therefore, the insulinotropic effect of fatty acids is influenced in a major way both by their chain length (positively) and by their degree of unsaturation (negatively). The latter point is further illustrated by the marked fall in potency of palmitoleate $\left(\mathrm{C}_{16: 1}\right)$ compared with 
that of palmitate (fold stimulation of GSIS, 16.2 and 3.1, respectively). Interestingly, the nature of the double bond (cis/ trans) in the unsaturated fatty acids had at best only a modest influence on GSIS, in agreement with a brief report by Alstrup et al. (13).

It should be noted that the difference in insulinotropic potency between octanoate and the longer chain saturated fatty acids tested here, as profound as it was, was almost certainly underestimated. This is because the free concentration of the medium chain fatty acid must have been much higher than that of palmitate or stearate, given its vastly greater water solubility. It may also be concluded that the greater effectiveness of saturated versus unsaturated long chain fatty acids was not the result of a higher unbound concentration of the former species. Indeed, the affinity for albumin actually increases (and the unbound/free concentration decreases) with the degree of saturation of the fatty acid (14).

The results described here appear to be in serious conflict with those of Opara et al. (15), who examined the effects of some of the same fatty acids on insulin secretion by perifused murine islets. That report would leave the impression that $(a)$ while palmitate is modestly stimulatory towards GSIS, linoleate is inhibitory; and $(b)$ stearate greatly suppresses basal insulin output. We have difficulty in interpreting these data, however, in view of the extremely high concentration of fatty acids used ( $5 \mathrm{mM}$ with only $2 \%$ albumin), and because the fatty acids were never present simultaneously with a stimulatory level of glucose. Moreover, only six islets were used per experiment, and the enhancement of insulin secretion caused by shifting the glucose concentration from 5.5 to $27.7 \mathrm{mM}$ (threefold) was very low compared with that usually observed in the intact pancreas.

Some intriguing questions are now posed. For example, why does fasting bring about an absolute dependence of the rat islet on fatty acids for GSIS? Although a firm answer is not yet available, one possibility, discussed previously (7), is that in the fed state the $\beta$ cell is capable of metabolizing glucose efficiently to the level of malonyl-CoA. This in turn would suppress the activity of mitochondrial carnitine palmitoyltransferase I, and thus cause an increase in the cytosolic concentration of fatty acyl-CoAs (derived either from intracellular lipid stores or from the low level of plasma FFA) which have been implicated as important signaling molecules for insulin secretion (16). If with food deprivation the pathway from glucose to malonyl-CoA is suppressed (e.g., because of diminished activity of pyruvate dehydrogenase or acetyl-CoA carboxylase, as in the liver), acute elevation of the cytosolic fatty acyl-CoA level might not be possible. The deficit, however, could be made up by provision of external fatty acids. Alternatively, it is conceivable that starvation simply brings about depletion of a critical lipid moiety that works in concert with glucose to trigger insulin secretion, and the effective concentration of which can be restored acutely by exogenous fatty acids. Whatever the precise role of fatty acids in GSIS, it is evident that it transcends the simple provision of energy to the $\beta$ cell, or else the readily oxidizable medium chain substrate, octanoate (17), would be expected to be highly stimulatory. Obviously this is not the case, as longer chain fatty acids, particularly when fully saturated, are much more insulinotropic. To what extent the signaling entity is the fatty acid itself, its CoA ester, an esterified product, or a combination of these species $(7,18)$, remains to be elucidated, as does the question of whether fatty acids are also instrumental in stimulus-secretion coupling by nonglucose secretagogues.

Despite the above unknowns, it is becoming increasingly clear that, at least in the rat, at any given time the output of insulin from the pancreas will be governed not only by the blood glucose level, but also by the prevailing concentration and nature of the circulating unbound fatty acids. To the extent that this paradigm also applies to humans, it is tempting to speculate that an excessively high ratio of saturated to unsaturated fatty acids in this plasma pool might promote hypersecretion of insulin, and thus contribute to the constellation of disorders, including hyperinsulinemia, dyslipidemia, and insulin resistance, that frequently accompanies the overconsumption of dietary saturated fat (19-25). In this regard, it is of interest that epidemiological studies in twins (21), in subjects with coronary artery disease (20), and in populations of aging men $(22,23)$, all suggest that high saturated fat intake is independently associated with hyperinsulinemia after accounting for known covariates such as levels of obesity and the aging process itself. Finally, it should be emphasized that the current studies have dealt with acute and physiological effects of fatty acids on insulin secretion in the rat. Whether chronic hyperlipacidemia can actually cause impairment of $\beta$ cell function in both rodents and humans is still a matter of debate $(6,26-28)$.

\section{Acknowledgments}

We are indebted to Ben Alexander for expert technical assistance with animal surgery, and to Dr. Brian Jefferson for fatty acid analyses.

This work was supported by grants from the National Institutes of Health (DK-18573), the NIH/Juvenile Diabetes Foundation Diabetes Interdisciplinary Research Program, Sandoz Pharmaceuticals, the Chilton Foundation, and the Forrest C. Lattner Foundation, Inc.

\section{References}

1. Greenough, W.B., S.R. Crespin, and D. Steinberg. 1967. Hypoglycemia and hyperinsulinaemiain response to raised free-fatty acid levels. Lancet. ii: 1334-1336.

2. Seyffert, W.A., Jr., and L.L. Madison. 1967. Physiologic effects of metabolic fuels on carbohydrate metabolism. I. Acute effect of elevation of plasma free fatty acids on hepatic glucose output, peripheral glucose utilization, serum insulin, and plasma glucagon levels. Diabetes. 16:765-776.

3. Crespin, S.R., W.B. Greenough, and D. Steinberg. 1973. Stimulation of insulin secretion by long-chain free fatty acids. A direct pancreatic effect. $J$. Clin. Invest. 52:1979-1984.

4. Balasse, E.O., and H.A. Ooms. 1973. Role of plasma free fatty acids in the control of insulin secretion in man. Diabetologia. 9:145-151.

5. Tamarit-Rodriguez, J., E. Vara, and J. Tamarit. 1984. Starvation induced changes of palmitate metabolism and insulin secretion in isolated rat islets stimulated by glucose. Biochem. J. 221:317-324.

6. Boden, G., X. Chen, J. Rosner, and M. Barton. 1995. Effects of a $48 \mathrm{~h}$ fat infusion on insulin secretion and glucose utilization. Diabetes. 44:1239-1242.

7. Stein, D.T., V. Esser, B. Stevenson, K.E. Lane, J.H. Whiteside, M.B. Daniels, S. Chen, and J.D. McGarry. 1996. Essentiality of circulating fatty acids for glucose-stimulated insulin secretion in the fasted rat. J. Clin. Invest. 97: 2728-2735.

8. Chen, S., A. Ogawa, M. Ohneda, R.H. Unger, D.W. Foster, and J.D. McGarry. 1994. More direct evidence for a malonyl-CoA-carnitine palmitoyltransferase I interaction as a key event in pancreatic $\beta$-cell signaling. Diabetes. 43: $878-883$.

9. Hamilton, J.G., and K. Comai. 1988. Rapid separation of neutral lipids, free fatty acids and polar lipids using prepacked silica sep-pak columns. Lipids. 23:1146-1149.

10. Malaisse, W.J., F. Malaisse-Lagae, and P.H. Wright. 1967. Effect of fasting upon insulin secretion in the rat. Am. J. Physiol. 213:843-848.

11. Grey, N.J., S. Goldring, and D.M. Kipnis. 1970. The effect of fasting, diet, and actinomycin D on insulin secretion in the rat. J. Clin. Invest. 49:881889 .

12. Burch, P.T., M.D. Trus, D.K. Berner, A. Leontire, K.C. Zawalich, and 
F.M. Matschinsky. 1981. Adaptation of glycolytic enzymes: glucose use and insulin release in rat pancreatic islets during fasting and refeeding. Diabetes. 30: 923-928.

13. Alstrup, K.K., S. Gregersen, and K. Hermansen. 1996. Differential effects of cis and trans fatty acids on insulin release from isolated mouse islets of Langerhans. Diabetologia. 39:A113.

14. Richieri, G.V., and A.M. Kleinfeld. 1995. Unbound free fatty acid levels in human serum. J. Lipid Res. 36:229-239.

15. Opara, E.C., M. Garfinkel, V.S. Hubbard, W.M. Burch, and O.E. Akwari. 1994. Effect of fatty acids on insulin release: role of chain length and degree of unsaturation. Am. J. Physiol. 266:E635-E639.

16. Prentki, M., S. Vischer, M.C. Glennon, R. Regazzi, J.T. Deeney, and B.E. Corkey. 1992. Malonyl-CoA and long chain acyl-CoA esters as metabolic coupling factors in nutrient-induced insulin secretion. J. Biol. Chem. 267:58025810.

17. Berne, C. 1975 . The metabolism of lipids in mouse pancreatic islets. The oxidation of fatty acids and ketone bodies. Biochem. J. 152:661-666.

18. Warnotte, C., P. Gilon, M. Nenquin, and J.C. Henquin. 1994. Mechanisms of the stimulation of insulin release by saturated fatty acids: a study of palmitate effects in mouse $\beta$-cells. Diabetes. 43:703-711.

19. Grundy, S.M., and M.A. Denke. 1990. Dietary influences on serum lipids and lipoproteins. J. Lipid Res. 31:1149-1172.

20. Maron, D.J., J.M. Fair, and W.L. Haskell. 1991. Saturated fat intake and insulin resistance in men with coronary artery disease. The Stanford coronary risk intervention project investigators and staff. Circulation. 84:2020-2027.

21. Mayer, E.J., B. Newman, C.P. Quesenberry, Jr., and J.V. Selby. 1993.
Usual dietary fat intake and insulin concentrations in healthy women twins. $\mathrm{Di}$ abetes Care. 16:1459-1469.

22. Parker, D.R., S.T. Weiss, R. Troisi, P.A. Cassano, P.S. Vokonas, and L. Landsberg. 1993. Relationship of dietary saturated fatty acids and body habitus to serum insulin concentrations: the normative aging study. Am. J. Clin. Nutr. 58:129-136.

23. Hannah, J.S., and B.V. Howard. 1994. Dietary fats, insulin resistance, and diabetes. J. Cardiovasc. Risk. 1:31-37.

24. McGarry, J.D. 1994. Disordered metabolism in diabetes: have we underemphasized the fat component? J. Cell. Biochem. 55 (Suppl.):29-38.

25. Rasmussen, O., F.F. Lauszus, C. Christiansen, C. Thomsen, and K. Hermansen. 1996. Differential effects of saturated and monounsaturated fat on blood glucose and insulin responses in subjects with non-insulin-dependent diabetes mellitus. Am. J. Clin. Nutr. 63:249-253.

26. Lee, Y., H. Hiroshi, M. Ohneda, J.H. Johnson, J.D. McGarry, and R.H. Unger. 1994. $\beta$-cell lipotoxicity in the pathogenesis of non-insulin-dependent diabetes mellitus of obese rats: impairment in adipocyte- $\beta$-cell relationships. Proc. Natl. Acad. Sci. USA. 91:10878-10882.

27. Zhou, Y.P., and V.E. Grill. 1995. Long term exposure to fatty acids and ketones inhibits $\beta$-cell function in human pancreatic islets of Langerhans. $J$. Clin. Endocrinol. Metab. 80:1584-1590.

28. Paolisso, G., A. Gambardella, L. Amato, R. Tortoriello, A. D'Amore, M. Varricchio, and F. D'Onofrio. 1995. Opposite effects of short- and long-term fatty acid infusion on insulin secretion in healthy subjects. Diabetologia. 38: 1295-1299. 